\title{
Energy Loss Estimation and Flow Simulation in the skimming flow Regime of Stepped Spillways with Inclined Steps and End Sill: A Numerical Model
}

\author{
Amirmasoud Hamedi \\ Department of Civil and Environmental Engineering, \\ Florida International University \\ Miami, FL, USA
}

\author{
Milad Ketabdar \\ Department of Civil and Environmental Engineering, \\ Lamar University, \\ Beaumont, TX, USA
}

\begin{abstract}
Energy dissipaters in dams consider as expensive structures; therefore, economic design of these structure are desirable. Stepped spillways can be use as energy dissipater to reduce the size and cost of the stilling basin. Hard experimental works, high-cost and time-consuming laboratory methods brought about some difficulties to determine the most-efficient design of the steps. This research deals with comparing the two-dimensional numerical simulation and experimental description in stepped spillways equipped with inclined steps and end sill together and presents a quick, trustworthy, economical, and numerical approach to designing the steps. In complicated geometries, simulation is more problematic than simulation of flow in horizontal steps, because it needs more precision around the end sills. Finite volume method and the $k-\varepsilon$ standard model are proposed to simulate the flow pattern and evaluate the energy loss over stepped spillway. The flow pattern and velocity vectors resulted from numerical simulation is in a good agreement with the experimental results. Also, energy losses resulted from the numerical approach have been compared with laboratory measurements and demonstrate reasonable agreement.
\end{abstract}

Keywords: stepped spillway; energy dissipation; inclined steps together with end sill; finite volume method; and k- $\varepsilon$ standard model; skimming flow regime

\section{INTRODUCTION}

Subgrade support system has a great influence on structures' behavior [1] [2]. Water flow from dam can damage downstream structures and expedite deterioration of their support system so a dissipate flow energy system is crucial to dams structural design. Dissipating energy over the chute may reduce the size of the stilling basin.In recent decades, several studies have addressed different aspects of stepped spillways; these studies have also introduced them as an efficient energy dissipater [3][4]. Three flow regimes can be seen over stepped chutes based on discharge rate. In the low-rate flows, Nappe flow regime is observed; and the Skimming Flow is caused by high discharge rates and between these two flow regimes Transition flow regime can be seen [3][4]. Chamani and Rajaratnam also Chanson Performed experiments on the Skimming Flow regime and devolved experimental formulas to determine the energy loss rate in this regime [5][6]. Some efforts has been made to use numerical simulation and machine learning in engineering [7] [8].Chen et al. used finite volume method and utilized the $\mathrm{k}-\varepsilon$ turbulent model to determine flow turbulence in stepped spillways [9]. Tabbara et al. simulated the flow over stepped spillway by the finite element method using ADINA software with the k- $\varepsilon$ standard turbulence model [10]. Mousavi-Jahromi et al. used ANSYS software to simulate the flow over stepped spillway [11]. They reported that numerical results have a six percent differential with experimental ones. The $\mathrm{K}-\varepsilon$ model was initially formulated by Spalding and Launder [12]. Two equations for the $k-\varepsilon$ turbulence model have been recognized as the appropriate formulas to simulate spillway flow. Other works have been conducted on flow condition, aeration, and energy loss in stepped spillways with horizontal steps. Boes and Hager [13], Cheng et al. [14], Estrella et al. [15] considered velocity and air concentration in air-water flow. Felder et al. did experimental study regarding air-water flow properties and energy dissipation [16], Gonzalez studied on free surface aeration [17], Ohtsu and Yasuda considered characteristics of flow conditions on stepped channels [18],
Toomes investigated air-water flow properties on low gradient stepped chutes [19], Zare and Doering worked on inception point of air entrainment and energy dissipation when stepped spillway equipped to baffles and sills [20] [21].

Moreover, other works on flow condition, and energy dissipation in stepped spillways equipped with inclined steps or an end sill, have been conducted and the results indicate that inclined steps are reduced more energy than horizontal steps [22] [23] [24] [25]. Among all the investigations conducted on spillways, the research performed by Chaturabul can be singled out [24]. In his research, the height of the applied end sills was considered at 5, 10, and 15 millimeters on various step slopes. The result of his investigation demonstrated that due to the existence of an end sill, relative energy loss increased 8\%. Chinnarasri and Wongwises examined inclined steps and the end sill to determine the energy dissipation rate independently [26]. They reported that using an end sill is the best method to increase the energy dissipation rate. As mentioned before, some researcher simulated flow over stepped spillways with horizontal steps, but no one had tried to simulate flow over stepped spillway equipped with inclined steps and an end sill together. In this kind of chutes, simulation is more difficult than horizontal steps, because more accuracy is needed accuracy around the end sills. In this paper, the finite volume method and the k- $\varepsilon$ turbulence model in FLUENT 6.3 have been utilized in twodimensional mode to estimate the energy loss also simulate the flow pattern, find velocity vectors and flow direction over a stepped spillway equipped with inclined steps with an end sill together. Flow depth and velocity are calculated numerically in specified sections, and energy loss is computed at each of these sections. Dimensionless parameters are used in this research to show the effectiveness of height and thickness of end sills on energy loss rate also experimental set up and results are presented then in the numerical part of the research, reasons to select grid type, boundary condition type and turbulence model are discussed. In the end, the effectiveness of the proposed numerical model to simulate the 
flow pattern, velocity vectors, flow direction and evaluate energy loss rate in a stepped spillway equipped with inclined steps with an end sill are discussed.

\subsection{Energy Loss Equations}

Chanson presented an equation in order to estimate dissipation energy rate in Skimming flow in stepped spillways [6]:

$$
\frac{\Delta H}{H_{\max }}=1-\frac{\left(\frac{f}{8 \sin \theta}\right)^{\frac{1}{3}} \cos \theta+\frac{1}{2}\left(\frac{f}{8 \sin \theta}\right)^{\frac{-2}{a}}}{\frac{H_{D}}{h_{c}}+\frac{3}{2}}
$$

Where $\mathrm{f}$ can be obtained as follows:

$$
\frac{1}{\sqrt{f}}=2.43-0.2676 \ln \left(\frac{h_{g} \cos \theta}{D_{H}}\right)
$$

Where DH is hydraulic depth of flow. Foregoing equation is applicable for mild slope chutes $\left(\theta \leq 20^{\circ}\right)$. Another equation, which can be used for determining the dissipation energy rate in the Skimming flow regime, is the utilization of Chanson's equation to calculate the remaining energy at the end of the chute. [6]

$$
H_{\text {res }}=y \cos \theta+\frac{q^{2}}{2 g y^{2}}+z
$$

Where $y$ is depth of fresh water and Hres is remaining energy at the end of the chute. The following equation is to calculate y:

$$
\frac{y}{h_{c}}=\sqrt[x]{\frac{f}{8 \sin \theta}}
$$

$\mathrm{f}$ is calculated from (2). The following equation has been also offered by Chamani and Rajaratnam in order to estimate the remaining energy at the end of the chute. [5]

$$
H_{r e g}=y_{m} \cos \theta+\frac{u_{m}^{2}}{2 g}+z
$$

Where ym is mixed depth (air and water); um is mixed flow velocity and $\mathrm{z}$ is height from baseline.

\section{DIMENSIONAL ANALYSIS}

Buckingham's Pi Method, as one of the most appropriate methods in dimensional analysis, has been used in this study. Effective parameters for energy dissipation in sloped stepped spillways, include: discharge per unit width, flow head, step length, step height, slope height, and gravity acceleration [27]. In this research, other factors such as spillway slope, water density and number of steps are considered as follows. Effective factors for energy dissipation in a stepped spillway equipped with inclined steps and the end sill together include:

q: Discharge in the unit width of the spillway

s: The spillway slope
$E_{\mathrm{L}}$ : Energy loss

E0: Flow head

h: Step height

$\rho_{\mathrm{w}}$ : Water density

1: Step length

$\mathrm{N}$ : Number of steps

m: Height of (slope + end sill)

$\mathrm{t}$ : Thickness of the end sill

g: Gravity acceleration

$E_{\mathrm{L}}=E_{\mathrm{L}}\left(q, E_{0}, h, l, m, t, g, s, \rho_{w}, N\right)$

Dimensionless parameters resulted from Buckingham's Pi theories:

$f=\mathrm{f}\left(E_{\mathrm{L}}, q, E_{0}, h, l, m, t, g, s, \rho_{w}, N\right)$

The number of variables is $n=11$.

$\rho\left[M L^{-3}\right], g\left[L T^{-2}\right], h[L] m=3 \rightarrow$ Basic dimensions

$\pi=\mathrm{n}-\mathrm{m}=11-3=8$

$f\left(E_{L}, E_{0} h^{-1}, q \sqrt{\frac{1}{g h^{3}},} l h^{-1}{ }_{s} m h^{-1}{ }_{x} t h^{-1}{ }_{x} s_{x} N\right)=0$

$\varphi\left(\frac{E_{0}}{h}, q \sqrt{\frac{1}{g h^{a}}}, \frac{l}{h}, \frac{m}{h}, \frac{t}{h}, s_{x}, N\right)=0=E_{L}$

The performed dimensional analysis is for a stepped spillway equipped with inclined steps and the end sill together. In this research, only the " $m / h$ " dimensionless parameter is used.

\section{EXPERIMENTAL SETUP}

This research has been conducted at the Water Research Institute in Iran. Side walls and steps were made of Plexiglas. The broad-crested weir has been used as the spillway in the chute and the number of steps is 60 . In the present investigation, only four steps are inclined and equipped with the sill; all are placed after the middle of the chute (steps 3942). The horizontal length of the steps is 14 centimeters; the step height is 4.66 centimeters and the chute width is 1.33 meters. Flow depth and velocity have been measured during each test using a liminimeter (with a precision of 1 millimeter) and a pitot-tube, respectively. The experiments have been conducted for one discharge in the Skimming Flow regime (90 liters per second, $\mathrm{q}=0.0677 \mathrm{~m}^{2} / \mathrm{s}$ ). Flow discharge has been measured by the sharp crested weir at the end of the downstream chute. Characteristics of the used end sills are presented in Figure 1 and Table 1. Three different slopes of $7^{\circ}, 10^{\circ}$, and $12^{\circ}$, respectively, about the horizon were used. 
Table 1. End sill specifications

\begin{tabular}{cc}
\hline \multicolumn{3}{c}{$(\mathbf{p - t}) \mathbf{m m}$} \\
\hline $6-5$ & $6-10$ \\
$8-5$ & $8-10$ \\
$10-5$ & $10-10$ \\
$15-5$ & $15-10$ \\
\hline
\end{tabular}

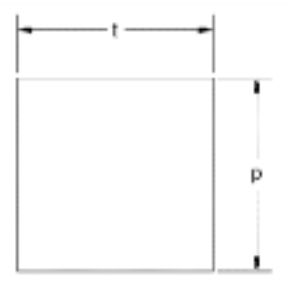

Figure 1. Schematic of the end sill

The depth along the spillway width was measured by a liminimeter across each line of the piezometers. Three depth measurement were recorded in each section because of insufficient liminimeter accuracy and the possibility of an outlook error. Finally, an average of these three depths across each line of the piezometer was used as the step depth. The pitot-tube was used to measure the velocity. This measurement was laborious, since the flow was a two-phase flow and bleeding had to be performed regularly. The velocity was measured on both sides and in the middle at 0.6 meters of depth. Finally, averages of these all three sections were averaged and set as the average velocity of that step. The piezometer was used to statically measure pressure fluctuation. These data points were used to enter pressures as initial values in a numerical simulation. In this chute, only four steps (39-42) were inclined and had sill. Depth and velocity values were measured on these steps, as well as on the 38th step.

The entrance flow from the reservoir into the chute flows through the transferring pipes from the pumps and falls into the reservoir. When the reservoir completely fills, the vent opens and flow falls into the chute. The utilized pump has a capacity of 220 liters per second. The following equations were used to determine upstream and downstream energy for the modified steps:

$$
\begin{aligned}
& H_{1}=y_{1}+\frac{V_{1}^{2}}{2 g}+z \\
& H_{1}=y_{1}+\frac{V_{1}^{2}}{2 g}+z
\end{aligned}
$$

Where $H$ is flow energy, $y$ is flow depth, $V$ is flow velocity in the proper sections, $g$ is gravity acceleration and $Z$ is the height above the baseline (The bottom of the last modified step has been assumed to be the baseline, and $Z=0$ ).

\section{A NUMERICAL APPROACH}

The numerical approach (Fluent 6.3) has been applied to simulate flow and estimate energy loss over stepped spillway equipped with an inclined step and an end sill, together. In this section, grid characteristics, the grid adaption method, boundary conditions, the turbulent model and the solver method details are discussed.

\subsection{Geometry and Meshing}

In the Finite Volume Method initial differential equations should be integrated into a physical space, and then should be solved using numerical methods. For that reason, point's grid should be developed directly in a physical space. Due to this, there is a non-zero probability that points in the grid don't relate to lines in the grid. These kind of grids are known as unstructured grids. A structured grid is easy to develop in simple geometry [28]. It needs less memory and time to resolve. However, in complex geometry, like the situation in this study, it is recommended to use unstructured grids with triangular elements. The required time to develop an unstructured grid in this study (complex geometry) is less than the required time to develop a structured grid. Although an unstructured grid needs more time and memory to solve the problem, it is still worth it to use in the study. The unstructured grid for this research was developed in Gambit software by triangular elements [29][30][31].

The Region Adaption Technique has been applied in this study. This technique makes triangular elements smaller around end sills, to achieve high accuracy. The grid has been divided into small triangles, depending on the required precision, (Figure 2) and considered 0.001 up to 0.01 meters, Also, to increase grid quality, smoothing and swapping have been applied. Smoothing rearranges cells to improve grid quality. It is recommended to use smoothing based on skewness when triangular elements have been used (Fluent 6.3 user's guide). For that reason, smoothing based on skewness has been applied to decrease the grid's maximum skewness. This method tries to decrease the skewness in cells with the skewness higher than the maximum limit, which is 0.4 in this study, by rearranging the cells. Furthermore, face swapping has been used to the grid to increase quality. In triangle cells, the Delaunay Method has been applied to improve grid quality.

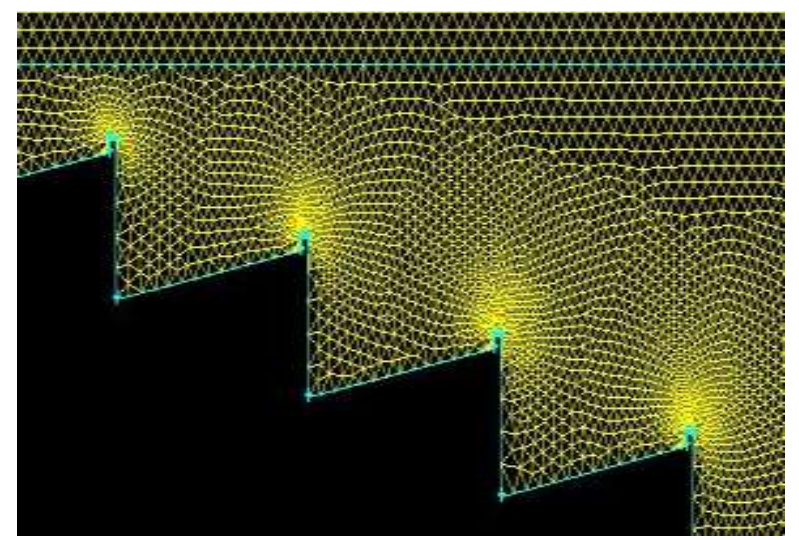

Figure 2. Applied unstructured grid 


\subsection{Initial and Boundary Condition}

There are two sections in the inlet (Figure 3), which are separated by the flow surface. In the lower section, the boundary type has been selected as velocity inlet, because this part is full of water with a certain velocity. The flow depth in each test is selected as height of this section. Also, the velocity in each test is entered into the software by magnitude and direction. The $\mathrm{x}$-direction is selected as a velocity direction. The second section is above flow, with the pressure equal to atmospheric pressure. For that reason, the pressure inlet boundary type is selected for this section. The area above the steps has a similar situation to the second section. Therefore, the pressure inlet boundary condition is selected for this area. In the outlet, there are two sections. The first section includes flow and the second one includes air. Because pressure inlet is selected in the inlet, the outflow boundary condition cannot be used in this section and the pressure outlet boundary condition should be used as boundary condition. In the end, the wall boundary condition has been applied to the steps.

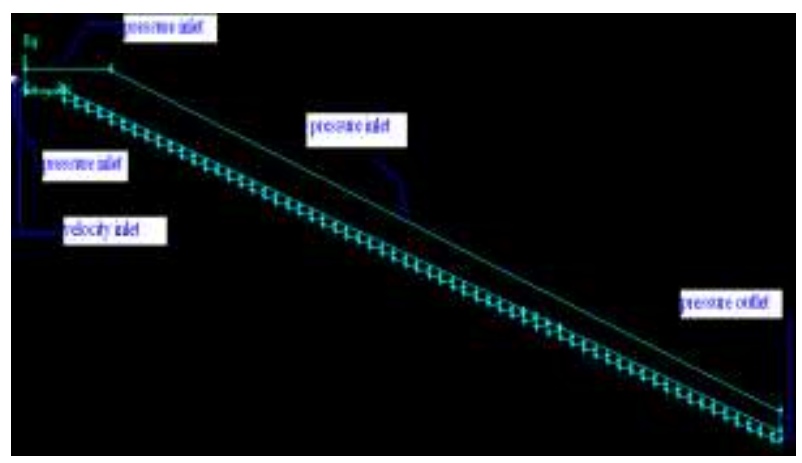

Figure 3. Boundary conditions

\subsection{Turbulence Modeling}

Both the water and air phases should be defined in the software to simulate he flow over the chute. The volume fraction is defined as " 0 " when the cell volume is out of water. The volume fraction is defined as " 1 " when the cell volume is full of water. The software will calculate the volume fraction of each cell based on the water and air percentage in that particular cell.

When the Reynolds number is large, or the geometry is complicated, it is impossible to solve time-dependent NavierStokes Equations completely. The Reynolds Average NavierStokes Equations (RANS) can solve the Navier - Stokes Equations in the way that turbulent flow fluctuations don't directly enter into the equations. In this method, new variables and extra quantities are introduced in governing equations. These new variables and quantities should be calculated by the turbulent models [30]. RANS Method has been applied in this research, because it can solve flows with a strong vortex and naturally unsteady flows with moderate cost. Among turbulent models, the Spalart- Allmaras, $k-\varepsilon, k-\omega$, and Reynolds Stress Model (RSM) use the RANS Method and all of them are available in Fluent 6.3. In the RANS Method, continuity and momentum equations are as follows [33]:

$$
\frac{\partial \rho}{\partial t}+\frac{\partial \rho u_{i}}{\partial x_{i}}=0
$$

$$
\begin{aligned}
& \frac{\partial \rho u_{i}}{\partial t}+\frac{\partial}{\partial x_{j}}\left(\rho u_{i} u_{j}\right)= \\
& -\frac{\partial p}{\partial x_{i}}+\frac{\partial}{\partial x_{j}}\left[\mu\left(\frac{\partial u_{i}}{\partial x_{j}}+\frac{\partial u_{j}}{\partial x_{i}}-\frac{2}{3} \delta_{i j} \frac{\partial u_{k}}{\partial x_{k}}\right)\right] \\
& +\frac{\partial}{\partial x_{j}}\left(-\rho \overline{u_{i}^{r} u_{j}^{\prime}}\right)
\end{aligned}
$$

Where $\rho$ is density, $\mu$ is molecular viscosity, $t$ is time, $x_{i}$ is the coordinate component, $u_{i}$ is the velocity component, and $p$ is pressure. Reynolds stresses should be calculated to solve the problem with the RANS Method. One of the methods that can be used to calculate Reynolds stresses is the Boussinesq Hypothesis (equation 14), which has a reasonable calculation cost.

$$
-\rho \overline{u_{\imath}^{r} u_{j}^{r}}=\mu_{t}\left(\frac{\partial u_{i}}{\partial x_{j}}+\frac{\partial u_{j}}{\partial x_{i}}\right)-\frac{2}{3}(\rho k) \delta_{i j}
$$

Where $\mu_{t}$ is the turbulence viscosity. $\delta_{i j}=1$ when $\mathrm{i}=\mathrm{j}$ and $\delta_{i j}=0$ when $i \neq \mathrm{j}$. Some turbulent models like SpalartAllmaras, $k-\varepsilon$, and $k-\omega$ use the Boussinesq Hypothesis. The $k-\varepsilon$ style models (standard, RNG, and Realizable) and the $k$ $\omega$ turbulent models solve two equations to calculate turbulent viscosity. The number of equations denotes the number of additional Partial Differential Equations (PDEs) that should be solved.

Among the $k-\varepsilon$ style models (standard, RNG, and Realizable) and the $k$ - $\omega$ turbulent models, the $k-\varepsilon$ standard is selected to be considered in this study as the first turbulent model attempt, due to its simplicity and reasonable cost. Furthermore, it has been previously used to successfully simulate flow over stepped spillways [9]. This turbulent model solves " $k$ " and " $\varepsilon$ "equations as additional PDEs to find turbulent viscosity. " $k(t)$ " is an instantaneous kinetic energy and is the sum the mean kinetic energy $(K)$ and the turbulent kinetic energy $(k) . k$ and $\varepsilon$ (simplified) are as follows:

$$
\begin{aligned}
& \frac{\partial(\rho k)}{\partial t}+\operatorname{div}(\rho k U)= \\
& \operatorname{div}\left[\left(\frac{\mu_{t}}{\sigma_{k}}\right) \operatorname{gradk}\right]+2 \mu_{t} E_{i j} E_{i j}-\rho \varepsilon
\end{aligned}
$$

$$
\begin{aligned}
& \frac{\partial(\rho \varepsilon)}{\partial t}+\operatorname{div}(\rho \varepsilon U)= \\
& \operatorname{div}\left[\left(\frac{\mu_{t}}{\sigma_{\varepsilon}}\right) \operatorname{grad} \varepsilon\right]+C_{1 \varepsilon} \frac{\varepsilon}{k} 2 \mu_{t} E_{i j} E_{i j} \\
& -C_{2 \varepsilon} \rho \frac{\varepsilon^{2}}{k}
\end{aligned}
$$


There are five terms in both equations. From left to right, the terms are the rate of increase, convective transport, diffusive transport, the rate of production, and the rate of destruction, respectively. Where $\mu_{t}$ is calculated by the following equation using $k$ and $\varepsilon$ (turbulence energy dissipation rate):

$$
\mu_{t}=\rho c_{\mu} \frac{k^{2}}{\varepsilon}
$$

Where $\rho$ is the fluid density, $c_{u}$ is the experimental constant and equals to 0.09 . Prandtl's turbulence numbers for $k$ and $\varepsilon$ consist of $\sigma_{\mathrm{k}}=1.0, \quad \sigma_{\varepsilon}=1.3, \quad \mathrm{C}_{1 \varepsilon}=1.44$ and $\mathrm{C}_{2 \varepsilon}=1.92$, which are the constants of the relation $\varepsilon$ [34]. The Second Order Implicit pressure based solver has been applied in this research. Moreover, the segregated algorithm has been used, because it needs less memory than the coupled algorithm. Furthermore, the First Order Upwind Method has been applied in turbulent kinetic energy and turbulent dissipation rate equations. The PISO method has been applied as a pressure velocity coupling method.

\section{RESULTS AND DISCUSSION}

The energy loss outcomes from the horizontal steps was 0.3514 and 0.3508 , respectively, derived from the Chanson equations (Equations 2 to 5) and from the test (Equations 10 and 11), which shows acceptable agreement. The changes were then applied to the steps, and the energy loss was measured for various slopes and end sills. In this section, the parameter $m=(p+w)$ is used, where $p$ is the height of the end sill, and $\mathrm{w}$ is the height of the step inclination (Figure 4).

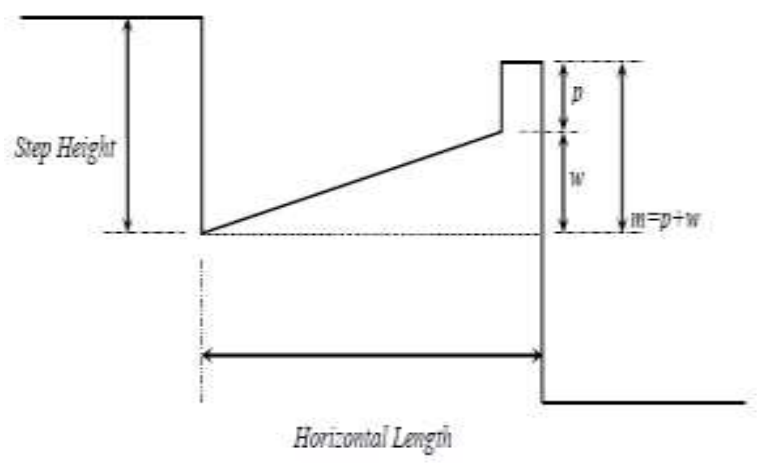

Figure 4. Schematic of the step

In Figure 5, it is obvious that if the " $m / h$ " ratio increases, up to 0.7 , the energy loss rate increases. After that, it decreases. This graph indicates that the best ratio for " $\mathrm{m} / \mathrm{h}$ " is about 0.7 , and an excessive increase negatively affects the energy loss rate. When the " $m / h$ " ratio goes past 0.7 , the flow jumps from one or more steps and the energy loss rate decrease (Figures $6 \mathrm{a}$ and $6 \mathrm{~b}$ ). This step plays practically no role in energy dissipation. As a consequence, the energy loss rate decreases.

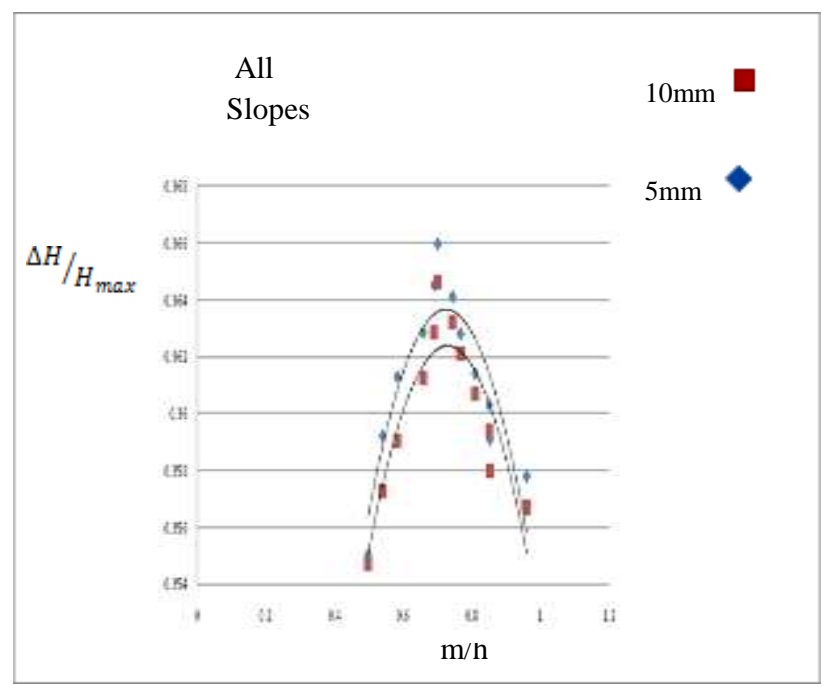

Figure 5. Energy dissipation loss per "m" for all examined slopes

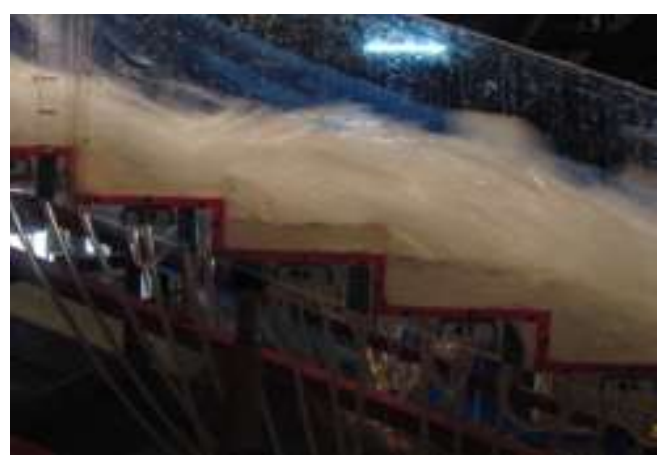

Figure 6 a. Slope $7^{\circ}$, height of end sill $=6 \mathrm{~mm}$ and thickness $=5 \mathrm{~mm}$

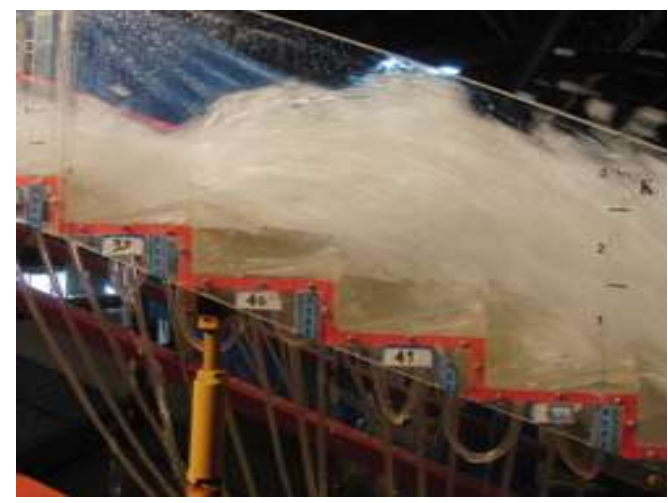

Figure 6 b. Slope $=12^{\circ}$, height of end sill $=15 \mathrm{~mm}$ and thickness $=5 \mathrm{~mm}$ 
Table 2 presents the results for the inclined steps and end sills for the " $\mathrm{m} / \mathrm{h}$ " equal to or greater than 0.7 (effective end sills). The outcomes indicate that the end sill height, as well as the step height incline (w), affect the energy dissipation rate slightly but thickness has no meaningful effect on energy loss rate. Table 2, also, indicates that "the maximum energy loss increase" is $4.13 \%$, and "the average energy loss increase" is $2.74 \%$. This amount of increase in the energy loss is not considerable and proves that step modification (inclined step and end sill) is not an effective technique to increase the stepped spillways' efficiency in terms of energy dissipation in skimming flow regime.

\section{Table 2. Comparison of energy losses derived from tests}

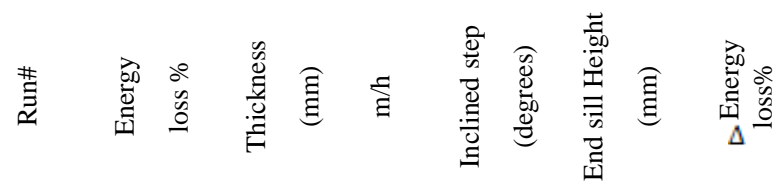

\begin{tabular}{ccccccc}
\hline 1 & 35.50 & 5 & 0.50 & 7 & 6 & 1.18 \\
2 & 35.92 & 5 & 0.54 & 7 & 8 & 2.39 \\
3 & 36.12 & 5 & 0.50 & 7 & 10 & 2.88 \\
4 & 36.28 & 5 & 0.66 & 10 & 6 & 3.31 \\
5 & 36.45 & 5 & 0.69 & 7 & 15 & 3.76 \\
6 & 36.59 & 5 & 0.70 & 10 & 8 & 4.13 \\
7 & 35.47 & 10 & 0.50 & 7 & 6 & 1.10 \\
8 & 35.72 & 10 & 0.54 & 7 & 8 & 1.79 \\
9 & 35.90 & 10 & 0.58 & 7 & 10 & 2.28 \\
1 & 36.12 & 10 & 0.66 & 10 & 6 & 2.96 \\
1 & 36.28 & 10 & 0.69 & 7 & 15 & 3.31 \\
1 & 36.46 & 10 & 0.70 & 10 & 8 & 3.78 \\
\hline
\end{tabular}

Numerical analysis results are presented as velocity vectors and water surface profile (Figures $7 \mathrm{a}$ and $7 \mathrm{~b}$ ). As it can be seen in Figure 6a, after the flow encounters the end sill in the first modified step, it jumps from the second and the third modified step. During the jump, some parts of the flow can't reach the last modified step and fall into the second and the third steps. Due to reverse inclined shape of the steps, this flow will stay in the second and the third steps and make a deep pool. The flow direction in the pool is from the end sill to the wall (from right to left) due to the step slope. Other parts of the flow jump to the last modified step, and during the jump combine with air, making highly aerated flow over the chute. Figure 7a shows the flow profile simulation. This flow profile is the same as the flow profile obtained in the laboratory. Also, flow direction is illustrated in Figure $7 \mathrm{~b}$ as velocity vectors. The flow direction is also similar to experimental results (Figure $7 \mathrm{~b}$ ). The velocity magnitude is larger in the jump flow and is smaller in the pool (Figure 7d). Experimental results confirm these values.

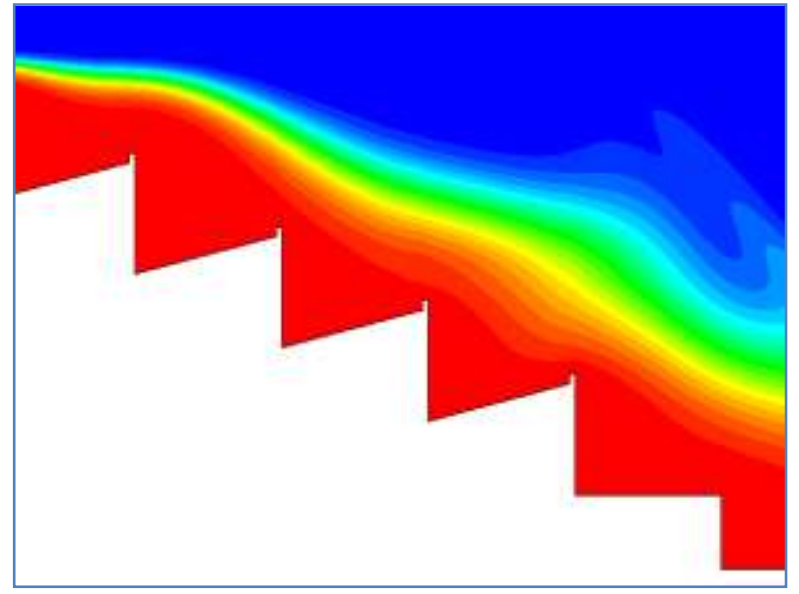

Figure 7a. Flow profile - Steep 10- End sill 6-5 mm

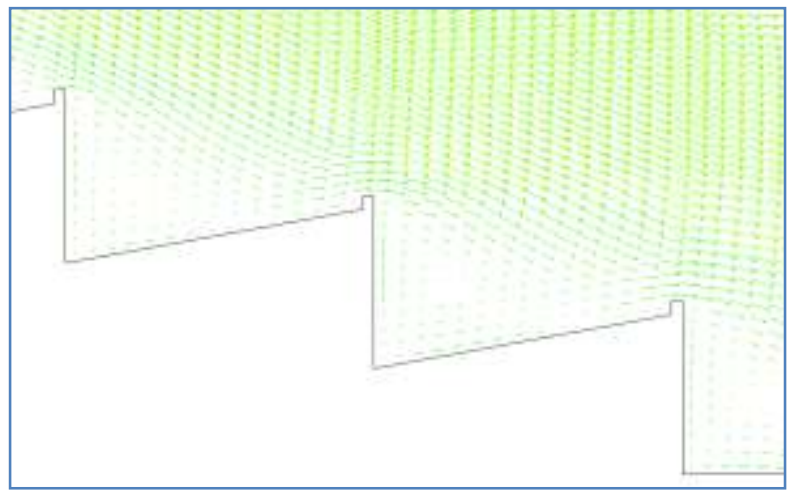

Figure $7 \mathrm{~b}$. Velocity vectors - Steep $10^{\circ}$ - End sill 6-5 $\mathrm{mm}$

Twelve tests have been performed in this research. The first eight tests are used for calibration, and other four tests are used for validation. In Table 3, there are eight tests which have been used to approach numerical calibration to simulate energy loss in the Skimming Flow regime. Moreover, the minimum error for calibration data is $5.37 \%$, and the maximum error is $9.91 \%$. Also, the average error for calibration data is $7.90 \%$. Table 4 indicates numerical simulation results in which validation data have been applied. The minimum error for validation data is $5.44 \%$, and the maximum error is $9.21 \%$. Moreover, the average error for validation data is $7.61 \%$. 
Table 3. Energy loss -Various end sills -Calibration

\begin{tabular}{|c|c|c|c|}
\hline \multicolumn{4}{|c|}{ Energy loss \% } \\
\hline$\underset{\sim}{\stackrel{\#}{\Xi}}$ & 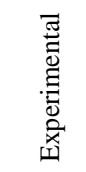 & 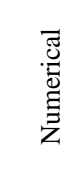 & 过 \\
\hline 1 & 35.50 & 37.78 & 6.03 \\
\hline 2 & 35.92 & 37.96 & 5.37 \\
\hline 4 & 36.28 & 38.99 & 6.95 \\
\hline 5 & 36.45 & 39.18 & 6.97 \\
\hline 7 & 35.47 & 39.37 & 9.91 \\
\hline 8 & 35.72 & 39.58 & 9.75 \\
\hline 10 & 36.12 & 39.79 & 9.22 \\
\hline 12 & 36.46 & 40.06 & 8.99 \\
\hline
\end{tabular}

Table 4. Energy loss - Varoious end sill - Validation

\begin{tabular}{|c|c|c|c|}
\hline \multicolumn{4}{|c|}{ Energy loss\% } \\
\hline $\begin{array}{l}\# \\
\Xi \\
\Xi\end{array}$ & 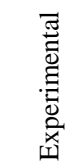 & 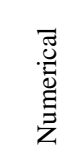 & 官 \\
\hline 3 & 36.12 & 38.20 & 5.44 \\
\hline 6 & 36.59 & 39.26 & 6.80 \\
\hline 9 & 35.90 & 39.45 & 9.00 \\
\hline 11 & 36.28 & 39.96 & 9.21 \\
\hline
\end{tabular}

\section{CONCLUSION}

In this study, four steps (39 to 42) have been modified and equipped with inclined steps and an end sill, together. End sills with several heights and thickness have been tested in three reverse stepped slopes (7, 10 and 12 degrees, respectively). The " $\mathrm{m} / \mathrm{h}$," has been used as a dimensionless parameter to determine the energy loss rate. Results denote that in the discharge $90 \mathrm{~L} / \mathrm{s}(\mathrm{q}=0.0667 \mathrm{~m} 2 / \mathrm{s})$, which represents the Skimming Flow regime, inclined steps and an end sill slightly increases the energy loss rate. The average of this increment is about $2.74 \%$ in effective end sills. Moreover, FLUENT 6.3 software was used in this research to simulate the flow over a stepped spillway. A numerical approach using the finite volume method, triangular elements, an unstructured grid and the $\mathrm{k}-\varepsilon$ standard turbulent model has been successfully applied to simulate flow pattern, velocity vectors in the complicated geometry of stepped spillways equipped with inclined steps and end sill together. Furthermore, the energy loss has been estimated using the numerical model. In the first step, eight tests (out of twelve) were selected for calibration; afterwards, four other tests were operated for validation. Numerical results for depth and velocity were used to calculate energy loss. The results illustrate some differences between the numerical and experimental outcomes. Average errors, generated by comparing the energy loss results between the experimental and numerical methods, were $7.90 \%$ and $7.61 \%$ for the calibration and validation data, respectively. The amount of these errors denotes that numerical models can be used as a low-priced and prompt method to estimate the energy dissipation rate in a stepped spillway equipped with inclined steps and end sills together.

\section{Acknowledgment}

The authors wish to acknowledge the support received in the form of a graduate assistantship from the Civil and Environmental Engineering Department, Florida International University. Also, the authors wish to acknowledge the Water Research Institute, Iran for providing the model and instruments to conduct experiments in the hydraulic laboratory.

\section{Notation}

The following symbols are used in this paper:

$\mathrm{c}_{1 \varepsilon}=$ Constant in the $\mathrm{k}-\boldsymbol{\varepsilon}$ turbulent model

$\mathrm{c}_{2 \varepsilon}=$ Constant in the $\mathrm{k}-\varepsilon$ turbulent model

$\mathrm{c}_{\mathrm{u}}=$ Constant in the $\mathrm{k}-\varepsilon$ turbulent model

$\mathrm{d}_{\mathrm{c}}=\quad$ Critical depth $(\mathrm{m})$

$\mathrm{E}_{0}=$ Flow head (m)

$\mathrm{E}_{\mathrm{L}}=$ Energy loss

$\mathrm{H}_{1}=$ Total head in section $1(\mathrm{~m})$

$\mathrm{H}_{2}=$ Total head in section $2(\mathrm{~m})$

$\mathrm{h}_{\mathrm{c}}=$ Critical depth $(\mathrm{m})$

$\mathrm{H}_{\text {dam }}=$ Dam height $(\mathrm{m})$

$\mathrm{H}_{\text {max }}=$ Total energy $\left(\mathrm{H}_{\mathrm{dam}}+3 / 2 \mathrm{~h}_{\mathrm{c}}\right)(\mathrm{m})$

$\mathrm{H}_{\mathrm{r}}=$ Residual height $(\mathrm{m})$ (Fratino and Piccini)

$\mathrm{h}_{\mathrm{s}}=$ Step height $(\mathrm{cm})$

$\mathrm{l}_{\mathrm{s}}=\quad$ Horizontal step length $(\mathrm{cm}, \mathrm{m})$

$\mathrm{u}_{\mathrm{i}}=$ Velocity component in the $\mathrm{x}$-direction $(\mathrm{m} / \mathrm{s})$

$\mathrm{u}_{\mathrm{i}}=$ Velocity component in the $\mathrm{y}$-direction $(\mathrm{m} / \mathrm{s})$

$\mathrm{u}_{\mathrm{k}}=$ Velocity component in the $\mathrm{z}$-direction $(\mathrm{m} / \mathrm{s})$

$\mathrm{u}_{i, j}^{r}=$ Velocity component in the $\mathrm{i}$ - or $\mathrm{j}$-direction (turbulent) $(\mathrm{m} / \mathrm{s})$

$V_{1}=$ Velocity in section $1(\mathrm{~m} / \mathrm{s})$

$\mathrm{V}_{2}=$ Velocity in section $2(\mathrm{~m} / \mathrm{s})$

$\mathrm{y}_{2}=$ Depth in section $2(\mathrm{~cm})$

$\rho_{\mathrm{w}}=$ Water Density $\left(\mathrm{kg} / \mathrm{m}^{3}\right)$

$\sigma_{\mathrm{k}}=$ Constant in the $\mathrm{k}-\varepsilon$ turbulent model

$\sigma_{\varepsilon}=$ Constant in the $\mathrm{k}-\varepsilon$ turbulent model

$\left.y_{1}=1\right)$ Flow depth on step $(\mathrm{cm})$

2) Depth in section $1(\mathrm{~cm})$

$\mu_{t}=$ Turbulent viscosity

$\Delta H=$ Dissipated energy in the length of the chute

$\mathrm{a}=\quad$ Variable in the Chamani and Rajaratnam Equation

$\mathrm{b}=\quad$ Variable in the Chamani and Rajaratnam Equation

$\mathrm{g}=$ Gravitational acceleration $\left(\mathrm{m} / \mathrm{s}^{2}\right)$

$\mathrm{h}=\quad$ Step height $(\mathrm{cm})$

$\mathrm{k}=\quad$ Turbulence kinetic energy

$\mathrm{l}=\quad$ Step length $(\mathrm{cm}, \mathrm{m})$

$\mathrm{L}=\quad$ Length in dimension analysis $(\mathrm{m})$

$\mathbf{M}=$ Mass in dimension analysis $(\mathrm{kg})$

$\mathrm{m}=$ 1) Height of slope + end sill (mm)

2) Basic variables (Pi Buckingham Theorem)

$\mathrm{n}=$ Number of variables in the Pi Buckingham Theorem 
$\mathrm{N}=\quad$ Number of steps

$\mathrm{P}=\quad$ End sill height $(\mathrm{mm})$

$\mathrm{q}=$ Unit discharge $\left(\mathrm{m}^{3} / \mathrm{m} . \mathrm{s}\right)$

$\mathrm{r}=\quad$ Basic (main) parameters in dimension analysis

$\mathrm{S}=$ Chute slope

$\mathrm{T}=\quad$ Time in dimension analysis (second)

$\mathrm{t}=\quad$ 1) End sill thickness $(\mathrm{mm})$

2) time (s)

$\mathrm{w}=$ Height caused by the slope in inclined step (mm)

$\mathrm{x}=$ Direction

$\mathrm{Z}=\quad$ Distance to the baseline $(\mathrm{m})$

$k=\quad$ All parameters in dimension analysis

$\alpha=\quad$ Energy loss coefficient

$\varepsilon=\quad$ Turbulence energy dissipation rate

$\mu=\quad$ Dynamic viscosity $(\mathrm{kg} . \mathrm{m} / \mathrm{s})$

$\pi=\quad$ Pi In Buckingham Method

\section{References}

[1] Sadeghi, J., \& Fesharaki, M. 2013. Importance of nonlinearity of track support system in modeling of railway track dynamics. International Journal of Structural Stability and Dynamics, 13(01), 1350008.

[2] Esmaeili, M., Sadeghi, J., \& Fesharaki, M. 2014, February. Vehicle dynamic interaction with railway track embankment. In Proceedings of the Institution of Civil Engineers-Transport (Vol. 167, No. 1, pp. 15-26). Thomas Telford Ltd.

[3] Chamani, M., \& Rajaratnam,. 1994. Jet flow on stepped spillways. Journal of Hydraulic Engineering 120 (1994): 254-259.

[4] Chanson, H. 1994. Comparison of energy dissipation between nappe and skimming flow regimes on stepped chutes. Journal of Hydraulic Research, 32: 213-218.

[5] Chamani, M. R., \& Rajaratnam, N. 1999. Characteristics of skimming flow over stepped spillways. Journal of Hydraulic Engineering, 125(4), 361-368.

[6] Chanson, H., Yasuda, Y., \& Ohtsu, I. 2002. Flow resistance in skimming flows in stepped spillways and its modelling. Canadian Journal of Civil Engineering, 29(6), 809-819.

[7] Bardestani, S., Givehchi, M., Younesi, E., Sajjadi, S., Shamshirband, S., \& Petkovic, D. 2016. "Predicting turbulent flow friction coefficient using ANFIS technique." Signal, Image and Video Processing, 1-7.

[8] Sajjadi, S., Shamshirband, S., Alizamir, M., Yee, L., Mansor, Z., Manaf, A. A., ... \& Mostafaeipour, A. 2016. "Extreme learning machine for prediction of heat load in district heating systems." Energy and Buildings, 122, 222-227.

[9] Chen, Q., Dai, G., \& Liu, H. 2002. Volume of Fluid Model for Turbulence Numerical Simulation of Stepped Spillway Overflow. Journal of Hydraulic Engineering, $128: 683-688$.
[10] Tabbara, M., Chatila, J., \& Awwad, R. 2005. Computational simulation of flow over stepped spillways. Computers and Structures, 83: 2215-2224.

[11] Musavi-Jahromi, H., Bina, M., \& Salmasi, F. 2008. Physical and numerical modeling of the nappe flow in the stepped spillways. Journal of Applied Sciences, 8: $1720-1725$.

[12] Launder, Edward, B., \& Spalding, Dudley Brian. 1972 Lectures in mathematical models of turbulence.

[13] Boes R. M.Hager W.H. 2003. Hydraulic Design of Stepped Spillways. Journal of Hydraulic Engineering vol.129,No 9.,sep,page:671-679.

[14] Cheng, X., and Xuewei Chen. 2013. Numerical Simulation of Dissolved Oxygen Concentration in Water Flow over Stepped Spillways. Water Environment Research 85.5: 434-446.

[15] Estrella T., Soledad, et al. 2013. Velocity and air concentration in air-water flow: application on a stepped spillway without sidewalls.

[16] Felder, S., Guenther, P., \& Chanson, H. 2012. Airwater flow properties and energy dissipation on stepped spillways: a physical study of several pooled stepped configurations. School of Civil Engineering, The University of Queensland.

[17] Gonzalez C.A. 2005. An Experimental study of Free-surface Aeration on Embankment Stepped Chutes. Ph.D Thesis.University of Queensland.Department of Civil Engineering.

[18] Ohtsu, I. , and Yasuda, r. 1997. Characteristics of flow conditions on stepped channels. Proc., 27th IAHR.Biennal congree, Sanfrancisco, 583-588.

[19] Toomes L. 2002. Experimental study of Air-Water Flow properties on Low gradient stepped Cascades. Ph.D Thesis. U niversity of Queensland, Brisbane,Austraklia.

[20] Zare, H. K., \& Doering, J. C. 2012. Energy dissipation and flow characteristics of baffles and sills on stepped spillways. Journal of Hydraulic Research, 50 :192-199.

[21] Zare, H. K., \& Doering, J. C.2012. Inception Point of Air Entrainment and Training Wall Characteristics of Baffles and Sills on Stepped Spillways. Journal of Hydraulic Engineering, 138: 1119-1124.

[22] Hamedi, A., Mansoori, A., Malekmohamadi, I., \& Roshanaei, H. 2011. Estimating Energy Dissipation in Stepped Spillways with Reverse Inclined Steps and End Sill. In World Environmental and Water Resources Congress Reston, VA: American Society of Civil Engineers, Conference Proceeding :2528-2537.

[23] Hamedi, A., Malekmohammadi, I., Mansoori, A., \& Roshanaei, H. 2012. Energy Dissipation in Stepped Spillway Equipped with Inclined Steps Together with End Sill. In 2012 Fourth International Conference on Computational Intelligence and Communication Networks . IEEE

[24] Hamedi, A., Mansoori, A., Shamsai, A., \& Amirahmadian, S. 2014. The Effect of End Sill and Stepped Slope on Stepped Spillway Energy Dissipation. Journal of Water Sciences Research, $6: 1-15$. 
[25] Hamedi, A., Ketabdar, M., Fesharaki, M., \& Mansoori, A. 2016. Nappe Flow Regime Energy Loss in Stepped Chutes Equipped with Reverse Inclined Steps: Experimental Development. Florida Civil Engineering Journal, 2:28-37.

[26] Chaturabul, T. 2002. Experimental study of flow behavior through stepped channels with end sills. MS Thesis, King Mongkut's University of Technology, Thailand.

[27] Chinnarasri, C., \& Wongwises, S. 2006. Flow Patterns and Energy Dissipation over Various Stepped Chutes. Journal of Irrigation and Drainage Engineering, 132: 7076.

[28] Baqersad, M., Eslami, A., Haghighat, Rowshanzamir, M., Mortazavi Bak, H., 2016. Comparison of Coupled and Uncoupled Consolidation Equations Using Finite Element Method in Plane-Strain Condition. Civil Engineering Journal, 2: 375-388.

[29] Munta, S., Otun, J., 2014. Study of the Inception Length of Flow over Stepped Spillway Models. Nigerian Journal of Technology, 33: 176-183.

[30] Naderi Rad, I., 2016. Application of Numerical Methods in Design of Hydraulic Structures. Communications on Advanced Computational Science with Applications, 1:1-15.

[31] Shahheydari, H., Jafari, E., Barati, R., Azhdary, M., 2015. Discharge coefficient and energy dissipation over stepped spillway under skimming flow regime. KSCE Journal of Civil Engineering, 19:1174-1182.

[32] Wilcox, D. C. 1998. Turbulence modeling for CFD DCW industries La Canada, CA, 2: 103-217.

[33] Rodi, W., 1993. Turbulence models and their application in hydraulics. CRC Press.

[34] Torrano, I., Tutar, M., Martinez-Agirre, M., Rouquier, A., Mordant, N., Bourgoin, M., 2015. Comparison of Experimental and RANS-Based Numerical Studies of the Decay of Grid-Generated Turbulence. Journal of Fluids Engineering, 137(6): 061203. 